Wang Peiyan*, Geng Xiaoliang, Zhao Chen, and Zhang Rongshuo

\title{
An investigation of the stitching effect on single lap shear joints in laminated composites
}

https://doi.org/10.1515/secm-2019-0028

Received February 8, 2018; accepted February 27, 2019

\begin{abstract}
This paper aimed to investigate the stitching effect on the bond strength of single lap shear joints in carbon/epoxy composite laminates using experimental and simulation methods. Stitched and unstitched single lap shear joints were bonded using the EC-3448 epoxy adhesive and tested under different working environments, including room temperature/dry (RTD), elevated temperature/wet (ETW) and cold temperature/dry (CTD). The results showed that stitching improved the bond strength of the stitched single lap joints, with approximately $60 \%$ higher strength for stitched compared to unstitched lap joints under RTD and CTD environments and 10\% higher strength under an ETW environment. The increase was smaller under ETW conditions because the adhesive recured under elevated temperature. Embedded interactions connected the lapping plates and the stitch line, and the maximum stress failure criterion was adopted for the stitch line. As the predicted failure modes are consistent with the experimental results, the progressive damage mode can be applied to simulate stitched composite structures.
\end{abstract}

Keywords: Stitching, Cohesive, Single lap joints, ETW

\section{Introduction}

Due to their excellent stiffness/weight ratio, integral molding, easy of design, and other features, composite structures are widely employed in the aerospace, civil and mechanical industries. For example, the Boeing 787 and Airbus A350XWB contain more than $50 \%$ by weight advanced composite components. Integral molding is the key feature differentiating composite materials from traditional metal materials. Integral molding products greatly reduce

\footnotetext{
*Corresponding Author: Wang Peiyan: School of Mechanics, Civil Engineering and Architecture, Northwestern Polytechnical University, Xi'an 710129, P.R. China, E-mail: pyxhx@just.edu.cn Geng Xiaoliang, Zhao Chen, Zhang Rongshuo : School of Mechanics, Civil Engineering and Architecture, Northwestern Polytechnical University, Xi'an 710129, P.R. China
}

the number of fasteners and lighten the weight of structures, for example, in reinforced panels and in the aircraft tail. Integral molding technology mainly uses cocuring technology to establish connections between components. The main failure mode of composite adhesive joints is delamination in the thickness direction between lap jointed sheets [1]. To improve the interlaminar strength of the joints, methods of reinforcement in the thickness direction should be considered. Stitching technology is already used in the field of composite laminates [2]. Therefore, stitching has been used in adhesive joints to improve shear strength [3]. The study of stitched joints began in 1985. Sawyer [4, 5] studied the effect of various parameters on the static and fatigue properties of single lap joints with the parameters including the adhesive thickness, the overlap length, the suture pitch, and the number of rows of sutures. In 1990, Long L [6-8] studied the static performance of a glyph stitched single lap joint and developed a method to predict the strength of lap joints. In 1998, Jain LK $[9,10]$ studied the effects of stitching on the fatigue life of composite single lap joints. The research showed that stitch lines were still intact after the crack extension and that the presence of stitch lines greatly improved the fatigue properties of lap joints. In 2004-2005, F. Aymerich [11-13] used experimental and simulation methods to study the effect of stitching on the static and fatigue properties of single lap shear joints. Several researchers [13-15] have studied the effect of stitching on single lap joints, but their conclusions have been inconsistent. For example, the study by Jain [10] showed that the stitch line could improve the static and fatigue joint strength, but the study by F. Aymerich [13] showed that the stitch line improved joint fatigue strength but reduced static strength. The performance of stitched joints is mainly controlled by the type of composite material, the suture conditions and the processing technology. Few researchers have studied the impact of environmental factors on the performance of stitched composite material joints, such as temperature and humidity. To establish a model considering the effects of temperature and humidity on the connection performance of joints, more detailed theoretical and experimental work is required.

This paper describes an investigation of the effect of stitching on the bond strength of single lap shear joints. 
Stitched and unstitched single lap joints were tested under different environments, and a detailed finite element model was established for numerical simulation with embedded interactions. The simulation results were compared with the experimental results to explain the effect of stitching on single lap joints.

\section{Experimental methodologies}

\subsection{Test specimens}

Fig. 1 presents a sketch of the single lap joint tested in this study. The lapping plates studied here were made of the composite laminate G0827/BA9912. The layup information is listed in Table 1, and the mechanics properties are detailed in Table 2. Paste adhesive EC-3448 was used between the two lap panels. Both the stitched and unstitched composite single lap joints tested in this paper were made by vacuum assisted resin infusion molding technology (denoted as VARI). The modified lock stitch was used (Fig. 2) with a stitching parameter of $5 \times 5 \mathrm{~mm}$.

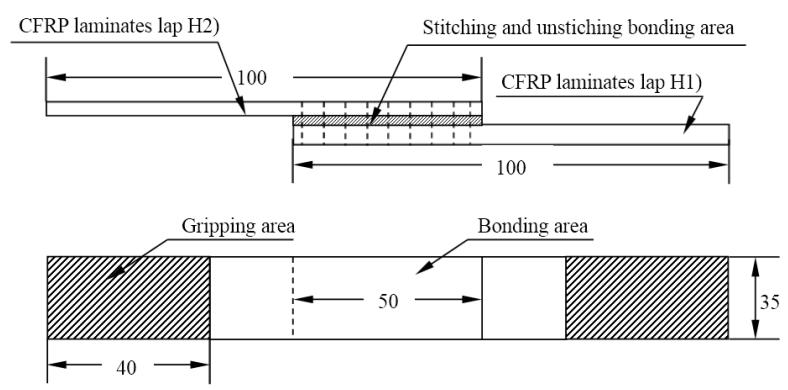

Figure 1: Geometry of the single lap joints

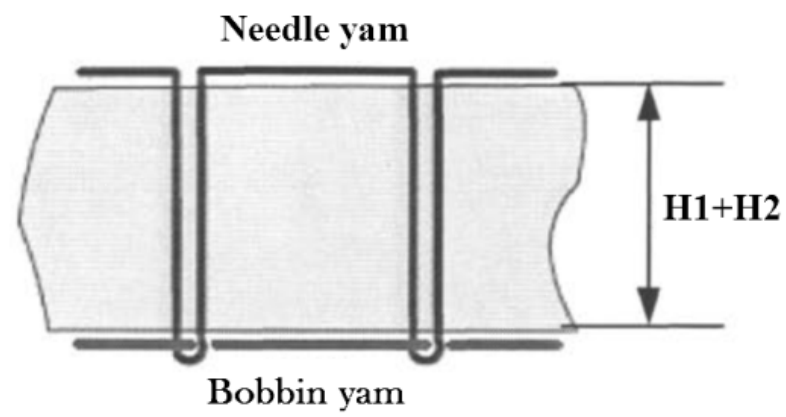

Figure 2: A modified lock stitch

\subsection{Test equipment and procedure}

Stitched and unstitched single lap joints were tested under different environments. The experiments were grouped into three types: RTD (room temperature/dry), CTD (cold temperature/dry) and ETW (elevated temperature/wet). The cold temperature was $55^{\circ} \mathrm{C}$ below zero, while the elevated temperature was $70^{\circ} \mathrm{C}$. Six specimens were tested in each group, for a total of 36 specimens. The load was applied at a crosshead speed of $1 \mathrm{~mm} / \mathrm{min}$ based on the HB7070 specifications. The single lap joints were subjected to static tensile tests using the INSTRON test machine with a load cell of 3T. The tests in the CTD and ETW environments were conducted in a chamber with the temperature controlled from $-70^{\circ} \mathrm{C}$ to $300^{\circ} \mathrm{C}$. The wet specimens were immersed in deionized water at $90^{\circ} \mathrm{C}$ for several days until the moisture reached equilibrium and then placed at the elevated temperature condition of $70^{\circ} \mathrm{C}$. An extensometer with a maximum measurement range of $25 \mathrm{~mm}$ was used to measure the elongation of single lap joint specimens. The experimental setup for the shear test of a single lap joint is shown in Fig. 3.

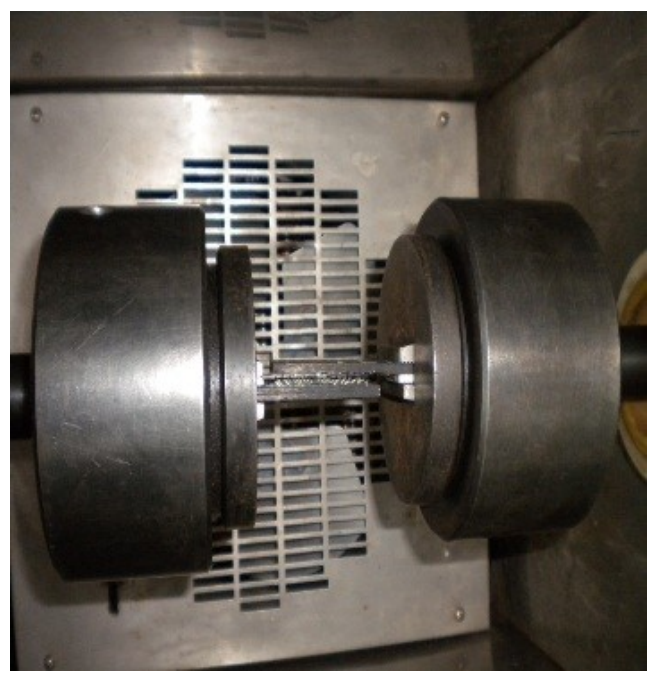

Figure 3: Experimental setup of the shear test

\section{Selected experimental results}

\subsection{Load-displacement curves}

A large amount of experimental data was obtained from these tests, but only a few representative results were chosen to present in the paper. Fig. 4 shows the load- 
Table 1: Layup information of the lapping plates

\begin{tabular}{lccc}
\hline Code & Materials (band) & Thickness $(\mathrm{mm})$ & Layup \\
\hline H1 & \multirow{2}{*}{ G0827/BA9916 } & 4.3 & {$\left[45 / 0 /-45 / 90 / 0 / 45 / 0 /-45 / 0_{2} / 45 / 0 /-45 / 90\right] \mathrm{s}$} \\
H2 & & 2.9 & {$[45 / 0 /-45 / 90 / 0 / 45 / 0 /-45 / 0] \mathrm{s}$} \\
\hline
\end{tabular}

Table 2: Mechanics properties of the test material

\begin{tabular}{ccc}
\hline & Symbol & G0827/BA9916 \\
\hline Moduli parameters & & \\
Longitudinal modulus & $\mathrm{E}_{1}(\mathrm{GPa})$ & 125 \\
Transverse modulus & $\mathrm{E}_{2}(\mathrm{GPa})$ & 9.58 \\
Shear modulus & $\mathrm{G}_{12}(\mathrm{GPa})$ & 5.38 \\
Poisson's ratio & $v_{12}$ & 0.3 \\
Strength parameters & & \\
Longitudinal tension & $\mathrm{X}_{t}(\mathrm{MPa})$ & 1835 \\
Longitudinal compression & $\mathrm{X}_{c}(\mathrm{MPa})$ & 1192 \\
Transverse tension & $\mathrm{Y}_{t}(\mathrm{MPa})$ & 73 \\
Transverse compression & $\mathrm{Y}_{c}(\mathrm{MPa})$ & 205 \\
Shear strength & $\mathrm{S}(\mathrm{MPa})$ & 94.7 \\
& & \\
Density & $\rho\left(\mathrm{g} / \mathrm{cm}^{3}\right)$ & 1.6 \\
\hline
\end{tabular}

displacement curves of stitched and unstitched single lap joints. The experimental data of single lap joints is presented in Table 3. The dispersion in the experimental data for stitched lap joints is considerably less than that for unstitched lap joints under all three environmental conditions (RTD, ETD or CTD). The main reason for the lower dispersion is that the strength of stitch line plays a key role in the bearing capacity of the stitched co-curing lap joints, and the strength dispersion of the stitch line is relatively small. In contrast, the bearing capacity of unstitched cocuring lap joints mainly depends on the adhesive strength of the matrix, which has a relatively large dispersion. To a large degree, the adhesive strength is related to the bonding process, adhesive thickness, surface quality of lapping plates [16-18].

Interfacial damage includes different models, such as model I, model II and model III. Model I is normal mode, model II is first shear mode and model III is second shear model. To describe interfacial damage initiation and evaluation, strain energy release rate is the key parameter. The strain energy release rate of model II is obtained from the stress-strain curves of the samples under shear loading, with the strain energy release rate approximately equal to the integral area of the stress-strain curve. The results can be used in the cumulative damage analysis of a single shear joint.

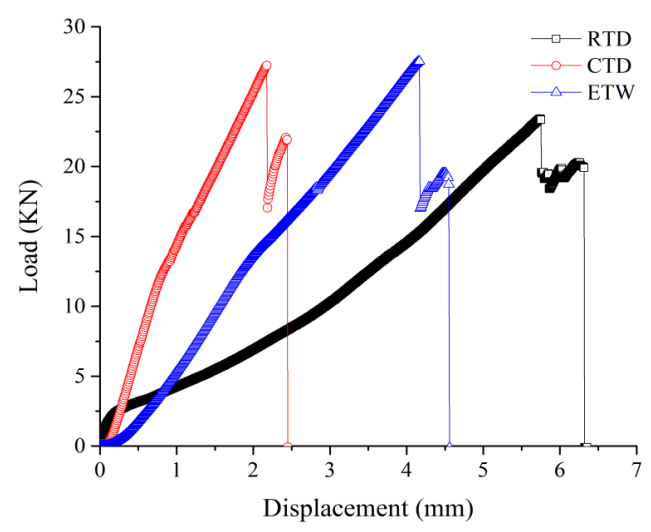

(a) Stitched joints

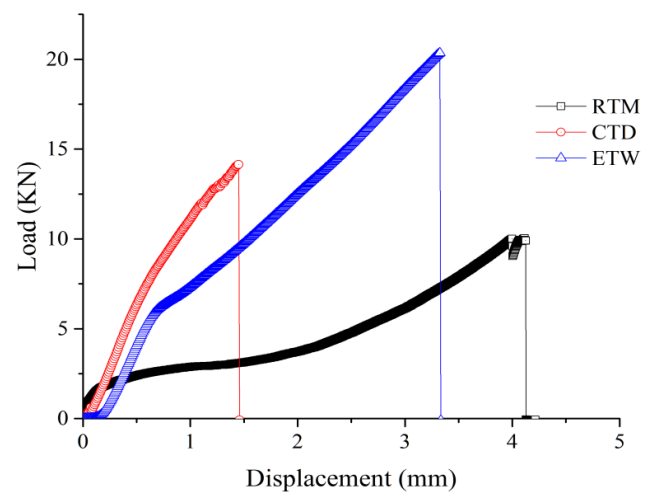

(b) Unstitched joints

Figure 4: Plots of load versus displacement

According to the J integral proposed by Rice [19], the boundary method can be written as:

$$
\int_{0}^{\delta_{\text {fail }}} \tau(\delta) d \delta=G_{C}
$$

where $G_{C}$ is the critical strain energy release rate, and $\delta_{\text {fail }}$ is the maximum displacement before the sample fails. $G_{I I}$ and $G_{I I I}$ are the critical strain energy release rates in mode II and mode III, respectively. The strain energy release rate of model II is similar to that of model III, denoted as $G_{I I}=$ $G_{I I I}$. The calculation results are shown in Table 4. 
Table 3: Joint strength of single lap joints (Units: MPa)

\begin{tabular}{lcccccc}
\hline Number & \multicolumn{3}{l}{ Stitched } & \multicolumn{5}{l}{ Unstitched } \\
\hline & RTD & CTD & ETW & RTD & CTD & ETW \\
\hline Joint-1 & 12.51 & 14.71 & 14.87 & 6.21 & 6.3 & 11.42 \\
Joint-2 & 14.01 & 14.29 & 12.43 & 5.69 & 7.5 & 11.09 \\
Joint-3 & 13.56 & 14.62 & 12.98 & 5.68 & 7.96 & 14.76 \\
Joint-4 & 12.76 & 14.04 & 14.14 & 5.47 & 7.48 & 13.18 \\
Joint-5 & 13.56 & 15.17 & 13.12 & 5.54 & 7.18 & 14.46 \\
Joint-6 & 14.76 & 14.37 & 15.76 & 7.1 & 6.14 & 11.38 \\
Mean value & 13.53 & 14.53 & 13.88 & 5.95 & 7.09 & 12.72 \\
Standard deviation & 0.82 & 0.39 & 1.27 & 0.62 & 0.72 & 1.65 \\
Variation & 6.08 & 2.71 & 9.15 & 10.44 & 10.19 & 12.94 \\
\hline
\end{tabular}

Table 4: Shear strength and strain energy release rate

\begin{tabular}{cccc}
\hline Molding process & Temperature environment & Shear strength $(\mathrm{MPa})$ & $\begin{array}{c}\text { Strain energy release } \\
\text { rate } G_{I I}\left(\mathrm{~kJ} / \mathrm{m}^{2}\right)\end{array}$ \\
\hline \multirow{3}{*}{ Stitched co-curing } & RTD & 13.53 & 28.840 \\
& CTD & 14.53 & 14.720 \\
& ETW & 13.88 & 25.296 \\
\hline \multirow{3}{*}{ Unstitched co-curing } & RTD & 5.95 & 7.396 \\
& CTD & 7.09 & 5.292 \\
& ETW & 12.72 & 11.80 \\
\hline
\end{tabular}

From Table 4, some results can be seen as follows. For the case of stitched lap joint, the shear strength values are close together, but for the strain energy release rate, the value of the CTD environment is minimum. For the case of unstitched co-curing, the shear strength values of the RTD environment is minimum, however, the strain energy release rate of the CTD environment is minimum. Shear strength is closely related to interfacial binding force, and stitched lap joints are mainly dependent on the properties of stitch, which has little change in CTD environment and ETW environment. So the stitched single lap joints were almost equal to each other in three environments. But the shear strength of unstitched single lap joints is almost dependent on the properties of adhesive. The adhesive become densification in cold temperature, but occur re-curing in high temperature. Therefore, the shear strength is minimum in RTD temperature. The strain energy release is related not only to shear strength, but also to fracture toughness. Because the adhesive and stitch become brittle in cold temperature, the strain energy release of both stitched and unstitched were minimum.

$G_{\text {equivC }}$ is the critical equivalent strain energy release rate calculated based on the user-specified model-mix criterion and the bond strength of the interface, and $G_{\text {equiv }}$ is the equivalent strain energy release rate at a node.
Abaqus/standard provides three common mode-mix formulas for the fracture criterion: the Benzeggagh-Kenane (B-K) law, power law, and Reeder law models. The choice of model is not always clear in any given analysis, and an appropriate model is best selected empirically. The B-K law is always used in aviation epoxy adhesives. $G_{\text {equiv } C}$ of the B-K law is shown in equation (2) [20]. If $G_{\text {equivC }}$ is greater than 1.0, the adhesive fails.

$$
G_{\text {equivC }}=G_{C}+\left(G_{C}-G_{C}\right)\left(\frac{G+G}{G+G+G}\right)
$$

\subsection{Failure mode}

The specimens were clamped in the special fixture, and the environmental chamber provided an accurate testing environment. In the early stage, the load-displacement curves were linear, and the specimens appeared undamaged. In the later stage, the specimen made a slight sound, and a large fluctuation occurred on the load-displacement curve. The sound was predicted to come from the rupture of fibers in the lap transition zone because of stress concentration. When failure occurred, the load-displacement curve dropped rapidly, and the load was not able to keep up with the load in displacement control. The main reason for this failure is that at the later loading stage, the lap 
interface had been damaged and that the effective lap area was reduced. Fig. 5 presents fracture photos of the stitched and unstitched single lap joints under a shear load. The location of damage was the interface between the lapping plates. For the unstitched single lap joints, a small amount of fiber is pulled out near the fracture surface. For stitched specimens, the fracture of the suture is flat, occurring at a highly uniform location. As for unstitched single lap joints, a small amount of fiber was also pulled out. The fiber always pulled out on the thinner lapping plate for stitched and unstitched lap joints.

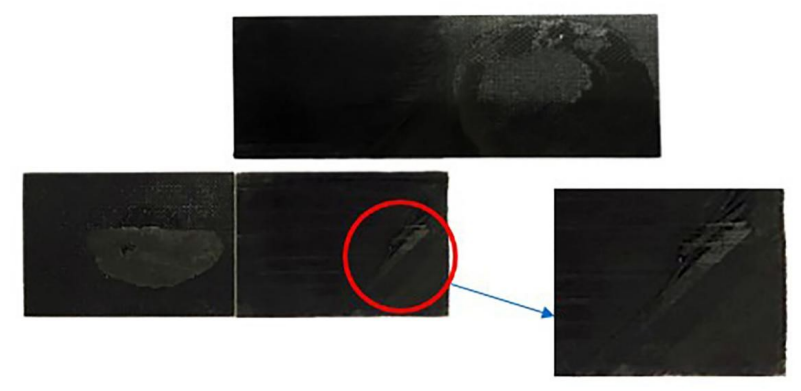

(a) Conventional unstitched co-curing lap joint

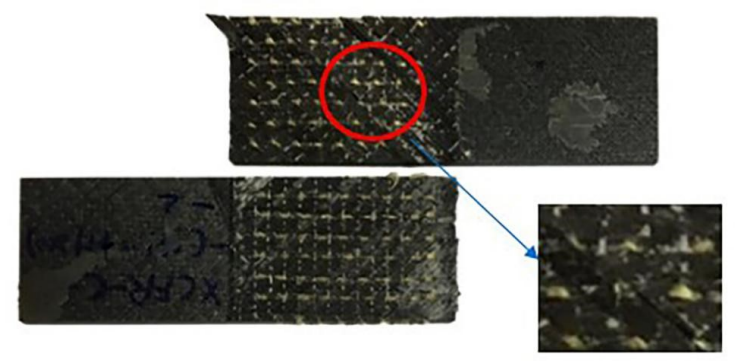

(b) Stitched co-curing lap joint

Figure 5: Damage photos

\subsection{Comparison and analysis}

The main results concerning the joint strength and failure modes of stitched and unstitched single lap joints are summarized as follows.

(1) Stitching can greatly improve the properties of single lap joints. In the RTD, CTD and ETW environments, the shear strength and fracture energy release of stitched single lap joints were considerably greater than those of unstitched joints, except in the ETW environment. Tests showed that the shear strength of stitched lap joints was up to 2.5 times that of conventional co-cured specimens and that the fracture energy release rate was up to 4 times greater. The main reason for this difference is that stitching technology improves the bond strength of shear joints.

(2) In the ETW environment, the bond strengths of the stitched and unstitched single lap joints were almost the same. The main reason for this result is that the EC-3448 paste adhesive re-cured at 85 degrees, resulting in a considerable increase in bond strength after re-curing. The EC3448 paste adhesive exhibits excellent heat resistance and humidity resistance below 90 degrees Celsius.

(3) Stitching technology enhances the interfacial properties, including the fracture energy release rate. In designing lap joints and stiffened composite panels, stitching technology can be carried out with appropriate parameters.

\section{Modeling strategies for numerical simulations}

To study the failure of stitched single lap joints, a single lap joint under shear force was simulated, and different failure criteria were considered. As the main joint fracture mode was interface debonding and fracture of the stitch line, stitch line failure and debonding of the interface between lapping plates were considered in the finite element model. The failure of composite materials was ignored in this simulation. The interface of the bonding area was established by cohesive elements, and the B-K law was used to simulate the interface failure. The stitch lines were modeled by truss elements with no compression properties. The stitch line is Kevlar29 (260 denier), where the diameter of one denier is $0.16 \mathrm{~mm}$. The failure of the suture is defined by the user subroutine USDFLD in the Abaqus software. As the fracture of the suture is almost brittle, this paper adopted a maximum stress failure criterion of a fracture tension of $50 \mathrm{~N}$. In the subroutine, FV represents field variable. If $\mathrm{FV}=0$, the properties under good conditions were chosen as the integration points; if $\mathrm{FV}=1$, the properties after stiffness reduction were chosen as the integration points.SDV is a state variable. If $S D V=0$, then the element is in a good state. If $\mathrm{SDV}=1$, then the element is in a state of failure. Progressive damage is defined as follows. The initial states of FV and SDV are set as 0. Firstly, the stress and strain of integration points are calculated. Then, the values of stress and strain are substituted into the failure criterion equation. If the value of the equation is greater than 1.0, FV and SDV are set as 1.0, and the reduced material properties are chosen at the integration points. If the value of the equation is smaller than 1.0, then the values of FV and SDV are still 0, and the unreduced material proper- 
ties are chosen. The stress and strain are calculated as the load increases. In this way, the simulation continues to estimate whether the integration points fail until the process does not converge and the integration points of the interface and stitch line all meet the failure criteria. The calculation process is shown in Fig. 6.

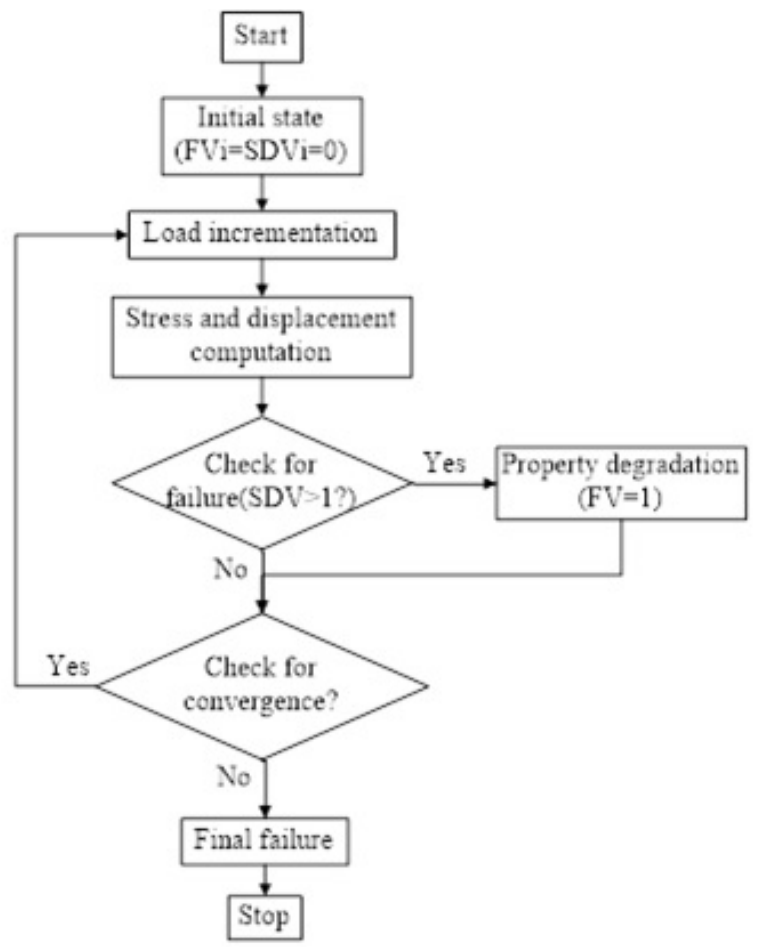

Figure 6: Flow chart of the progressive damage analysis

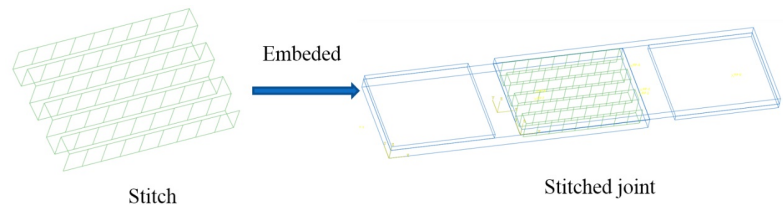

Figure 7: Geometric relationship between the stitch line and lapping plates

\subsection{Finite element modeling}

The method used to model the connection between the stitch line and the lapping plates is the key technology in modeling stitched composite structures.

After comparison with various modeling methods, a new, accurate, and simple method is proposed. The B2 el-

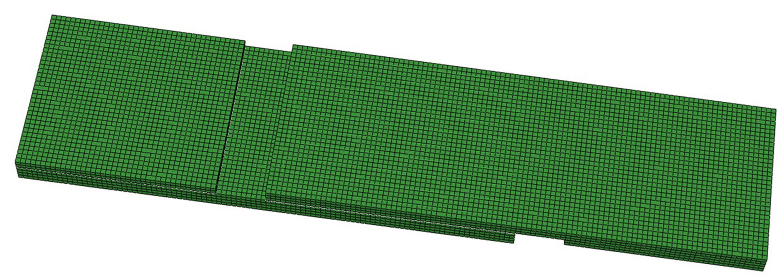

Figure 8: Finite element mode

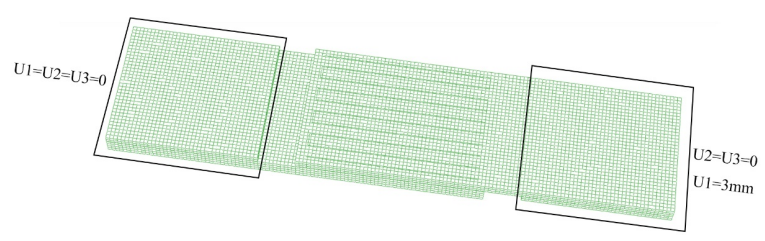

Figure 9: Load and boundary condition

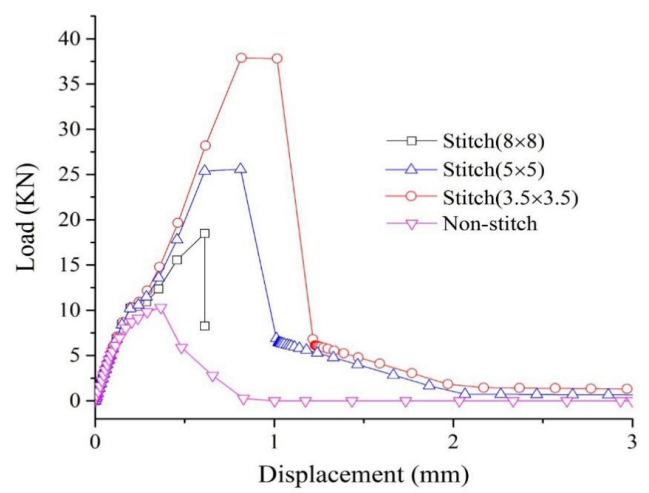

Figure 10: Load-displacement curves of different stitching parameters

ement is used for the stitch lines, and the C3D8 element is used for the lapping plates. The stitch lines and lapping plates were modeled, and the stitch line is connected with the lapping plates by embedded interactions. The geometric relationship is shown in Fig. 7. The finite element model and boundary conditions are shown in Fig. 8 and Fig. 9. The displacement force was applied on one end, and the shear strength was calculated by the reaction force of fixed end. The finite element model of the stitch line is in good agreement with the actual structure, which is also simple to model. The material parameters are defined according to the experimental results.

\subsection{Finite element model sensitivity studies}

To study the effect of the stitch density on the shear strength, three finite element models with different stitch 
densities were established. The stitch densities were $8 \times 8 \mathrm{~mm}^{2}, 5 \times 5 \mathrm{~mm}^{2}$ and $3.5 \times 3.5 \mathrm{~mm}^{2}$, and the unstitched single lap joint was also studied for comparison. The loaddisplacement curves are shown in Fig. 10.

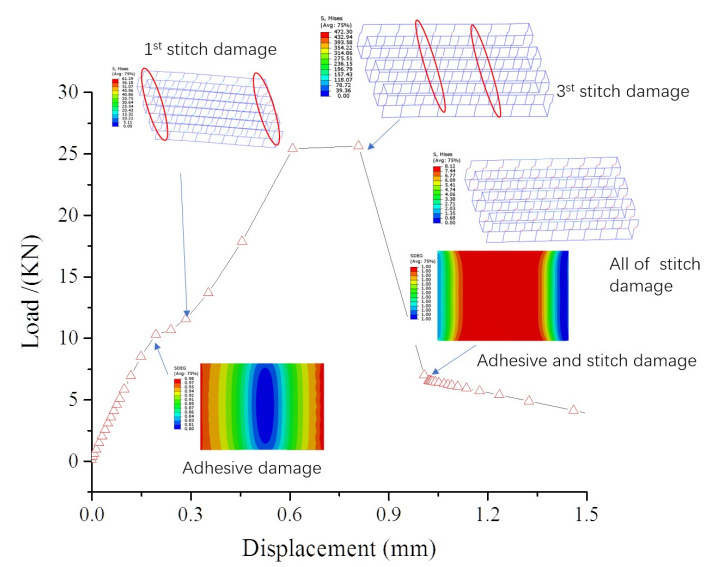

Figure 11: Curves of the interface damage generation and expansion of the stitched specimens
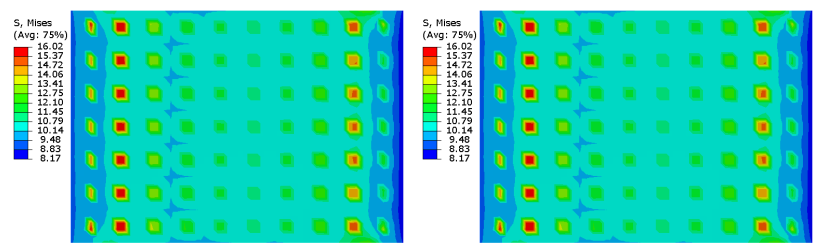

(a) $\mathrm{U}=0.21 \mathrm{~mm}, \mathrm{~F}=10 \mathrm{kN}$

(b) $\mathrm{U}=0.28 \mathrm{~mm}, \mathrm{~F}=11.5 \mathrm{kN}$

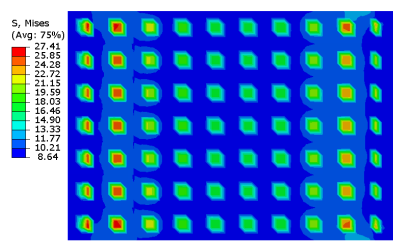

(c) $\mathrm{U}=0.6 \mathrm{~mm}, \mathrm{~F}=25.4 \mathrm{kN}$

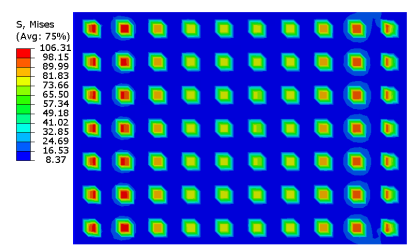

(d) $\mathrm{U}=0.8 \mathrm{~mm}, \mathrm{~F}=25.8 \mathrm{kN}$
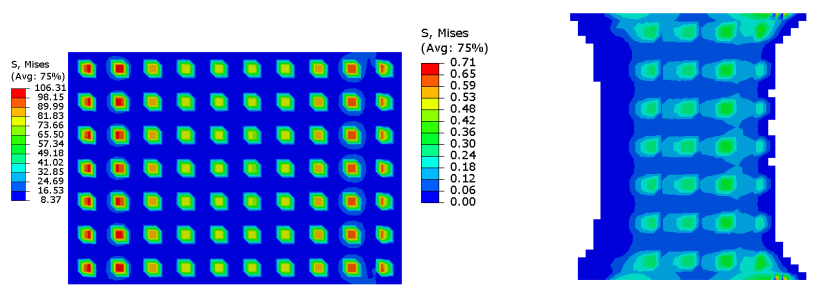

(e) $\mathrm{U}=1.0 \mathrm{~mm}, \mathrm{~F}=6.9 \mathrm{kN}$

(f) $\mathrm{U}=3.0 \mathrm{~mm}, \mathrm{~F}=0 \mathrm{kN}$
The error between the numerical result and the experimental result is less than $5 \%$. The experimental shear load of the stitched lap joint with a stitching parameter of $5 \times 5 \mathrm{~mm}^{2}$ is $23.7 \mathrm{kN}$, and the simulated result is $25.2 \mathrm{kN}$. The experimental shear load of the unstitched lap joint is $10.4 \mathrm{kN}$, and the simulated result is $10.1 \mathrm{kN}$. The model established in this paper can be used to simulate the failure of single lap joints, including stitched and unstitched lap joints.

The shear strength was considerably improved by stitching, and the bond strength increased rapidly with increasing stitch density. The stitched lap joint with a stitching parameter of $3.5 \times 3.5 \mathrm{~mm}^{2}$ had the greatest shear strength, almost 4 times greater than that of the unstitched lap joint.

Fig. 11 shows the damage generation and extension process for the stitched lap joint with the parameter of $5 \times \mathrm{mm}^{2}$. Fig. 12 shows the change in the stress distribution of the interface with displacement load. The cracks in the stitched shear specimens were initially generated at the edges of the adhesive layer and then spread to the stitch line. When the stress was greater than the maximum stress of the suture, the suture fractured. The first row of the stitch lines ruptured first. After that, the adhesive layer expanded a little further, and then, the second row of sutures fractured. The sutures and the adhesive layer failed one row at a time until all rows of the sutures fractured. The stress contour indicates that the position of the stitch line is the point of local stress concentration on the lap board. As the rigidity of the stitch line is much greater than that of the adhesive layer, the stitch line takes on most of the shear load. Alternatively, the stitch line can be said to block the extension of damage, and the rupture of the stitch line leads the crack to grow. As the fracture load increases, the shear strength of the interface is considerably improved.

When the displacement increased from $0 \mathrm{~mm}$ to $0.8 \mathrm{~mm}$ and the shear load increased from $0 \mathrm{kN}$ to $25.8 \mathrm{kN}$, the stitch line began to break. After that point, the stitch line gradually fractured, and the shear load decreased rapidly. This process is basically consistent with the experimental results.Therefore, the proposed simulation method can be used to predict the shear load of single lap joints of stitching composite materials.

\section{Conclusions}

The effect of stitching on the bond strength of single lap shear joints of carbon/epoxy composite laminates was in- 
vestigated using experimental and simulation methods. The shear properties of the stitched and unstitched composite single lap joints were investigated under RTD, CTD and ETW environments. A progressive approach to the damage analysis for stitched single lap joints was established. Some useful conclusions can be drawn based on the above findings.

(1) The bond strength of single lap joints was considerably improved by the stitching technology, especially in the RTD and CTD environments, and the bond strength increased rapidly with increasing stitch density.

(2) The ETW environment provided a suitable environment for the adhesive to re-cure, resulting in lap joints that exhibited good properties in the ETW environment. The stitching technology had little effect on lap joints for the EC-3448 paste adhesive.

(3) A finite element model was constructed using embedded interactions to connect the lapping plates and the stitch line, and the maximum stress failure criterion was adopted for the stitch line. The predicted failure modes were consistent with the experimental results, indicating that the progressive damage mode can be used to model stitched composite structures.

Acknowledgements: This investigation was supported by the Natural Science Foundation of Shaanxi Province(No. 2017JM5018), and National Science Foundation of China (No. 51305351). The authors would also like to deliver their sincere thanks to the editors and anonymous reviewers.

\section{References}

[1] Han-Gi Son, Yong-Bin Park, Jin-Hwe Kweon Jin-Ho Choi. Fatigue behaviour of metal pin-reinforced composite single-lap joints in a hygrothermal environment. Composite Structures, 2014, 108, 151-160.

[2] Kristopher P. Plain, Liyong Tong. An experimental study on mode I and II fracture toughness of laminates stitched with a one-sided stitching technique. Composites: Part A, 2011, 42, 203-210.

[3] H. Ghasemnejad, Y. Argentiero, T.A. Tez, P.E. Barrington. Impact damage response of natural stitched single lap-joint in composite Structures. Materials and Design, 2013, 51, 552-560.

[4] Sawyer JW. Effect of stitching on the strength of bonded composite single lap Joints. AIAA Journal, 1985, 23, 1744-1748.

[5] Lee C., Liu D. Tensile strength of stitching joint in woven glass fabrics. Journal of Engineering Materials and Technology, 1990, 112, 125-130.

[6] Tong L, Cleaves K, Kruckenber T, Steven GP. Strength of RTM single lap joints with transverse stitching. Key Engineering Materials, 1998, 137, 195-202.
[7] Tong L. Strength prediction of RTM single lap joints with transverse stitching. Journal of Engineering Materials and Technology, 1998, 120, 300-303.

[8] L. Tong and L. K. Jain. Analysis of Adhesive Bonded Composite Lap Joints with Transverse Stitching. Applied Composite Materials, 1995, 2, 343-365.

[9] Jain L. K., Leong KH, Mai YW, Tong L. Effect of through-thickness stitching on the fatigue life of composite single lap joint. Applied Composite Materials, 1998, 5, 399-409.

[10] Jain L. K., Mai YW. Analysis of resin-transfer-moulded singlelap joints. Composites Science and Technology, 1999, 59, 15131518.

[11] Aymerich F. Effect of stitching on the static and fatigue performance of co-cured composite single-lap joints. Journal of Composite materials, 2004, 38(3), 243-257.

[12] Aymerich F, Onnis R, Priolo P. Analysis of the fracture behaviour of a stitched single lap joint. Compos Part A, 2005, 36, 603-614.

[13] F.Aymerich, R. Onnis, P. Priolo. Analysis of the effect of stitching on the fatigue strength of single-lap composite joints. Composites Science and Technology, 2006, 66, 166-175.

[14] K.T. Tan, N. Watanabe, Y. Iwahori, T. Ishikawa. Understanding effectiveness of stitching in suppression of impact damage: An empirical delamination reduction trend for stitched composites. Composites: Part A, 2012, 43, 823-832.

[15] K.T. Tan, N. Watanabe, Y. Iwahori. Effect of stitch density and stitch thread thickness on low-velocity impact damage of stitched composites. Composites: Part A, 2010, 41, 1857-1868.

[16] Kimiyoshi Naito, Mutsumi Onta, Yasuo Kogo. The effect of adhesive thickness on tensile and shear strength of polyimide adhesive. International Journal of Adhesion \& Adhesives, 2012,36, 77-85.

[17] A.M. Pereira, J.M. Ferreira, F.V. Antunes, P.J. Bártolo. Analysis of manufacturing parameters on the shear strength of aluminium adhesive single-lap joints. Journal of materials processing technology, 2010, 210, 610-617.

[18] F. Heidarpour, M. Farahani, P. Ghabezi. Experimental investigation of the effects of adhesive defects on the single lap joint strength. International Journal of Adhesion and Adhesives, 2018, 80, 128-132.

[19] Fraisse, P. , Schmit, F.. Use of J-integral as fracture parameter in simplified analysis of bonded joints. International Journal of Fracture, 1993, 63, 59-73.

[20] Murat Demiral, Ferhat Kadioglu. Failure behviour of the adhesive layer and angle ply composite adherends in single lap joints: a numerical study. International Journal of Adhesion and Adhesives, 2018, 87, 181-190. 